Cuadernos de Relaciones Laborales ISSN: 1131-8635

http://dx.doi.org/10.5209/CRLA.56769

\title{
Trabajo autónomo y transformación del salariado: las reformas española y francesa
}

\author{
Sylvie Célérier ${ }^{1}$; Alberto Riesco-Sanz ${ }^{2}$; Pierre Rolle ${ }^{3}$
}

Recibido: 02 de junio de 2016 / Aceptado: 07 de octubre de 2016

Resumen. El artículo compara los procesos de reforma del trabajo autónomo puestos recientemente en marcha en España y en Francia. Se analiza, en primer lugar, la actuación de ambos Estados en dicho proceso para, posteriormente, abordar el carácter paradójico y ambiguo -a medio camino entre la independencia y la subordinación- que han revestido algunos de los estatutos de empleo impulsados por este proceso de reforma en ambos países. De este análisis comparativo se deducirá que, en ambos casos, la acción pública, más que ser desencadenante trata de responder a una sucesión de acontecimientos y mutaciones ya en marcha que apuntan a la existencia de un proceso de transformación del salariado de mayor calado, dentro del cual habría que situar y analizar las mutaciones del trabajo autónomo registradas.

Palabras clave: Subordinación; trabajo autónomo; estatuto de empleo; acción pública; figuras híbridas de empleo.

\section{[en] Self-employment and the transformation of the wage earning society: the spanish and french reforms}

\begin{abstract}
The article compares the self-employment reform process put in place in Spain and France. Firstly, we analyze the contribution of the two States to this process, showing how new employment statuses favored by the reform turn out a paradoxical and equivocal independent-dependent status. From this comparative approach we conclude that the public action is not triggering but following a transformation process already in progress. This process aims at a deeper transformation of the wage earning society that could explain changes registered in the Spanish and French self-employment.

Key words: Subordination at work; self-employment; job status; public management; hybrid forms of employment.
\end{abstract}

Sumario. 1. Introducción. 2. Una regulación atravesada por la actuación del Estado. 3. Un proceso de reforma ambiguo. 4. A modo de conclusión. 5. Bibliografía. 6. Anexo: resumen de los dispositivos jurídicos analizados.

Cómo citar: Céleriér, S; Riesco-Sanz, A.; Rolle, P. (2017). “Trabajo autónomo y transformación del salariado: las reformas española y francesa". Cuadernos de Relaciones Laborales 35(2), 393-314.

1 Université Lille1-Clersé

E-mail: sylvie.celerier@univ-lille1.fr

2 Universidad Complutense de Madrid-TRANSOC

E-mail: albertoriesco@ucm.es

3 Université Paris Ouest Nanterre-Ladyss

E-mail: rolle.pierre@wanadoo.fr 


\section{Introducción}

Desde hace algún tiempo los análisis sobre la dinámica del empleo llaman la atención sobre el carácter novedoso de ciertas figuras laborales que combinan trabajo asalariado y trabajo autónomo (D'Amours, 2014; Bureau y Corsani, 2012; Böheim y Mühlberger, 2009; Darbus, 2008; Perulli, 2003). La mayoría de las categorías de empleo suelen vincularse al contrato asalariado, diferenciándose según su duración, el tiempo de trabajo o los actores que en él intervienen. Sin embargo, las formas híbridas a las que aquí nos referimos desbordan el estricto perímetro de la empresa, reconociendo por primera vez formas de subordinación en un espacio de "libre intercambio" (el definido en torno al trabajo formalmente autónomo) donde dicha subordinación no tiene razón de ser jurídica. Y es que, como sabemos, tan sólo el contrato asalariado reconoce en el ámbito de la empresa tal subordinación como libremente consentida por parte del empleado, un trabajador cuya actividad es dirigida y coordinada con la actividad de otros por el empleador o por las figuras en las que éste delegue. El poder público, por su parte, interviene ampliamente en este contrato considerado a priori como privado, precisando y limitando los efectos de la autoridad del empleador, sometiéndole a obligaciones que configurarán derechos y protecciones adscritos al estatuto del trabajo asalariado.

Más allá de este ámbito de la empresa, el derecho mercantil regula el libre intercambio entre sujetos libres, verificando llegado el caso la conformidad del objeto, el precio y los plazos como en cualquier otro contrato singular. La ejecución del trabajo contratado es dejada en este caso a discreción de quien presta el servicio, y las obligaciones comerciales de quien lo contrata se limitan al abono del precio acordado. Aquí, aunque el poder público interviene igualmente -principalmente mediante la fiscalidad-, no busca con ello prevenir o contrarrestar un desequilibrio previo en las posiciones ocupadas por los actores presentes. De hecho, en caso de producirse tal desequilibrio sería la jurisprudencia la que, eventualmente, denunciaría al empleador ordenante, transformando el contrato (comercial) en un contrato asalariado. Tal y como puede pues apreciarse, los derechos y protecciones acordados a los trabajadores no tienen existencia jurídica más que como contrapartida de la subordinación del trabajador asalariado.

Desde este punto de vista resulta entonces comprensible que inquiete la emergencia de formas de empleo situadas en la interfaz de estos dos universos diferentes. A menudo se ha percibido tal emergencia como una consecuencia del desempleo masivo que expulsa a los asalariados fuera de las empresas y les transforma en trabajadores autónomos, sometidos a duraciones e intensidades de trabajo extremas para obtener clientes y asegurar la continuidad de sus ingresos. Estos nuevos trabajadores no gozarían ya de las protecciones arduamente peleadas por los asalariados a lo largo del siglo pasado, temiéndose el retorno de formas de trabajo extenuantes e inestables similares a las de los comienzos de la industrialización. La extensión de un fenómeno de estas características sería, no obstante, minoritario pues el estatuto del trabajo asalariado mantiene aún su hegemonía en las distintas modalidades de trabajo. Francia y España, por ejemplo, apenas cuentan con un 11,0\% y un $16,4 \%$ respectivamente de trabajadores autónomos dentro de su población ocupada (la UE-28 un 14,2\%) (Eurostat, Labour Force Survey, Q4, 2015), englobando además en dicho colectivo situaciones muy heterogéneas difíciles de anudar a un único movimiento de transformación. Algunos de estos trabajadores, por ejemplo, ejercen su actividad 
en la periferia de las empresas, contribuyendo y participando -a distancia y sin apenas protección- de su ecosistema. Para estas personas su antiguo empleador se ha convertido en su principal cliente, ahorrándose éste los costes del salario social: en lo sucesivo será responsabilidad de los trabajadores reproducir su propio capital, por limitado que éste sea ${ }^{4}$. Otros autónomos ejercen su actividad dentro de los propios muros de la empresa, se entremezclan con sus asalariados, participan directamente de la cooperación productiva aun cuando el empleador no tenga con respecto a ellos ninguna obligación específica (Célérier, 2012). Y los hay, finalmente, que se ajustan a lo que podríamos denominar como trabajadores autónomos "auténticos".

En cualquier caso, lo que podemos constatar es que por toda Europa el trabajo autónomo está siendo reformado 5 . Tales reajustes jurídicos - que impulsan la instalación por cuenta propia de trabajadores previamente asalariados- constituye la experiencia común de los algo más de 30 millones de trabajadores autónomos existentes en la Unión Europea (Eurostat, Labour Force Survey, Q4, 2015). Con el objetivo de comprender dicho movimiento, el presente artículo aborda la figura del auto-emprendedor implementada en Francia en 2009, así como el estatuto del trabajo autónomo instaurado en España en 2007 por medio de la Ley del Estatuto del Trabajo Autónomo (LETA) (cf. anexo al final de este artículo). La comparación de los casos de Francia y España se justifica en la medida en que ambos países encarnan dos vías de reforma del trabajo autónomo a priori claramente diferenciadas. Francia, por un lado, ha ampliado y reglamentado el estatuto del emprendedor individual instaurando la figura de un emprendedor que se mueve en el ámbito de la independencia pero al cual se adscriben al mismo tiempo elementos fundamentales del salario social (reforzando así el carácter híbrido de esta figura). Este nuevo estatuto ha logrado un éxito inmediato innegable: un año después de su creación, el 12\% de los trabajadores autónomos se habían adscrito al mismo, representando más de la mitad de las nuevas empresas creadas ese mismo año (Institut National de la Statistique et des Études Économiques-INSEE). España, por su parte, ha optado por un acercamiento al espacio del trabajo asalariado, considerando al autónomo como un "trabajador" al que podría incluso llegar a reconocérsele eventualmente su dependencia económica (tal y como ocurre con la categoría jurídica del trabajador autónomo económicamente dependiente). España se aproximaría así a la experiencia italiana del lavoro parasubordinato (Berton, Pacelli y Segre, 2005), si bien dotando a estos nuevos trabajadores de derechos y protecciones más amplias. Esta es la razón por la cual el dispositivo español ha sido presentado como innovador desde el punto de vista del derecho, como un modelo a seguir capaz de conjurar los riesgos presentes en el devenir del trabajo autónomo.

Estaríamos pues ante dos proyectos reformistas diferenciados que apuestan, no obstante, por dotar a los trabajadores externos a la empresa de derechos y protecciones cuyo disfrute dependería en teoría del sometimiento a la autoridad patronal. Dicha

$4 \quad$ Con el término de salario social nos referimos a un tipo de renta que se encuentra desvinculada del trabajador individual y que se encuentra distribuida entre el conjunto de los trabajadores en forma de gastos en escuelas, hospitales, ayudas al alojamiento, subvenciones de diverso tipo, etc. El término de salario indirecto suele emplearse de forma más restrictiva para hacer referencia exclusivamente a las cotizaciones sociales. La noción de salario social podría también englobar tales cotizaciones sociales (Rolle, 1988:136-138).

5 Véanse, por ejemplo, los casos de Bulgaria (Job Opportunities through Business Support Project-JOBS), Francia (régimen del auto-emprendedor), España (Estatuto del Trabajo Autónomo), Irlanda (Back to Work Enterprise Allowance-BTWEA), Italia (lavoro parasubordinato), Austria (Unternehmensgründungsprogramm). 
operación jurídica resulta, sin embargo, todo menos evidente. Tal y como hemos señalado, los trabajadores autónomos no tienen mayor vínculo con quien demanda sus servicios que el que se deriva de un acuerdo puntual, de forma que sus intercambios no dejan espacio, en principio, a una intervención jurídica como la existente en el trabajo asalariado. Resulta pues necesario recurrir a instituciones ad hoc encargadas de fijar los criterios y las normas a partir de los cuales se juzgará si estos trabajadores están sujetos a constricciones insuperables que pudieran justificar su equiparación al resto de asalariados. Son estas dimensiones y complejidades las que ambos dispositivos que estamos analizando (especialmente visible en el caso español) tratan de organizar. En ellos, la subordinación de los nuevos trabajadores autónomos no adopta la forma de una tutela permanente, sino que debemos descubrirla en la repetición de los intercambios puntuales con sus clientes, donde se ejecutan los mismos gestos, se efectúa el mismo proyecto o se aprueba el mismo tipo de inversión.

Las categorías jurídicas abren, como vemos, no pocos dilemas que, a menudo, limitan el alcance de nuestro análisis sobre las transformaciones en marcha. Debemos pues ir más allá de tales categorías jurídicas, adoptando un marco sociológico más amplio que, en nuestro caso, tomamos prestado de la sociología del salariado (Rolle, 1997; 1988; Naville, 1984). En dicho marco de análisis el trabajador no es definido por su contrato, sino por su inscripción en un dispositivo mercantil que condiciona su acceso a los intercambios sociales. El trabajo, desde este punto de vista, no abarca el conjunto de actividades existentes, a pesar de que muchas de ellas -sin ser trabajo- sirven para cubrir necesidades fundamentales. Desde la perspectiva que aquí estamos reivindicando, la distinción fundamental operada por el derecho entre trabajo autónomo y trabajo asalariado no tendría razón de ser y la propia categoría de "trabajador independiente" o de "trabajador autónomo" resultarían paradójicas. Autónomos o asalariados, todos se inscriben en un dispositivo mercantil del que obtienen los medios de subsistencia. Son, en este sentido, trabajadores y este elemento común prima, desde un punto de vista analítico, sobre la posible variedad de sus empleos. Todos ellos llevan así la marca de una subordinación que desborda las fronteras de la empresa y se organiza en la reproducción compleja de la sociedad salarial. Con esto no queremos decir que pese sobre ellos una constricción permanente: su libertad existe, aun cuando no pueda aspirar a ser total. A decir verdad, salariado y libertad individual son dos realidades completamente heterogéneas, siendo la primera de ellas de naturaleza colectiva. La coordinación de ambas realidades no es posible sino a costa de un colosal esfuerzo social -también colectivo-que podemos analizar como la esencia misma de lo político, aunque ésta sea ya otra cuestión.

Partiendo de esta concepción ampliada del trabajador y de la recomposición de las fronteras de la jurisdicción pública sobre el trabajo, los estatutos híbridos inventados por los Estados francés y español deben ser analizados como respuestas a las ambigüedades previamente existentes en sus marcos jurídicos nacionales. El análisis aquí efectuado sobre estos estatutos novedosos trata de rastrear su origen, operadores y posibles consecuencias, abordándolos en tanto que indicadores de un nuevo modo de gestión de la mano de obra por medio del cual ésta es desvinculada de su empresa y sometida a un nuevo colectivo de sujetos ordenantes. En una primera etapa de este programa de trabajo, el artículo intenta comprender cuál ha sido el papel desempeñado por ambos Estados en estas reformas. Al mismo tiempo, en un segundo momento, se procede a explorar el contenido de ambos dispositivos, comparándolos desde el punto de vista de las condiciones de acceso y de los derechos sociales 
más o menos ampliados a los que dan lugar. El examen llevado a cabo relativiza la aparente diferenciación existente entre ambas modalidades de reforma, así como la supuesta ventaja en materia de protección de la propuesta española. El análisis que aquí presentamos muestra, por el contrario, que a un lado y otro de los Pirineos, los nuevos estatutos de empleo tratan de situar a los trabajadores bajo la égida de las instituciones nacionales del salariado. Tales tentativas resultan, sin embargo, ambiguas y revisables, no logrando superar la paradoja original del derecho del trabajo: aquella que pretende contener la subordinación de los trabajadores en un contrato específico al que se adscribirían distintos privilegios.

\section{Una regulación atravesada por la actuación del Estado}

De manera casi simultánea, España y Francia han redefinido una parte de las modalidades de ejercicio del trabajo autónomo existentes en su territorio, generando incluso nuevas categorías laborales: los trabajadores autónomos económicamente dependientes (TRADE) en el caso español y los auto-emprendedores (AE) en el caso francés. Como suele ser habitual en materia laboral, la actuación del Estado se ha concretado, en primer lugar, en un ejercicio de categorización encaminado a registrar la singularidad de una situación de trabajo imposible de aferrar a partir de las codificaciones jurídicas existentes. La singularidad ahora reconocida consiste en una mezcolanza o hibridación de aquello que durante mucho tiempo fue pensado como dos formas antinómicas de empleo: por un lado, el trabajo denominado autónomo o independiente, generador de prestaciones de servicio sujetas al derecho mercantil; por otro lado, el trabajo asalariado, donde la actividad del trabajador queda enmarcada por un contrato de trabajo regulado al detalle por el derecho del trabajo.

Nos encontramos en ambos casos ante un intercambio de trabajo, pero un intercambio que se efectúa bajo condiciones diferenciadas. Para el trabajador autónomo, dicho intercambio se organiza en el marco de una sucesión de contratos coyunturales en los que debe precisarse en cada momento la naturaleza de la prestación a realizar, los plazos de entrega y las condiciones de su remuneración. Todo lo referido a la organización de tareas o al tiempo de trabajo es necesariamente dejado a iniciativa del trabajador autónomo. De no ser así, si el ordenante del servicio impusiera sus propias reglas, correría el riesgo de verse señalado por los tribunales de lo social como empleador y su relación laboral redefinida como asalariada (con las contrapartidas que ello conlleva). Y es que, tal y como mencionábamos previamente, el contrato asalariado sí atribuye esta potestad al empleador, una autoridad que el empleado acepta cuando firma su contrato de trabajo, enmarcando al mismo tiempo su intercambio laboral en una duración determinada. Al contrario de lo que sucede con la prestación de servicios del trabajo autónomo, la subordinación jurídica -central en el contrato de trabajo asalariado- genera un cierto derecho a la continuación de un contrato que se ejecuta de forma consecutiva (Gaudu, 1986). De este modo, el empleador se ve liberado de tener que precisar con antelación cada una de las tareas que quiere que se realicen: por medio del contrato del trabajo sus asalariados se comprometen a aceptar todas cuantas éste estime oportuno asignarles en el ámbito de su empleo, al igual que deberán aceptar su autoridad jerárquica y su potestad para organizar tales tareas. 
La emergencia de estas nuevas formalizaciones jurídicas pone en evidencia que la confluencia del derecho del trabajo y del derecho mercantil genera no pocas dificultades a las que los Estados tratan de encontrar una solución. Entre las múltiples dificultades detectadas llama nuestra atención la progresiva fragilización de las figuras constitutivas de ambos ámbitos del derecho. Así, al tiempo que se diluye el contorno de la forma empresa, las figuras del empleador, del ordenante del servicio, del autónomo o del asalariado resultan cada vez más difíciles de diferenciar entre sí. Desde este punto de vista cabría pensar las acciones emprendidas en España y en Francia como tentativas encaminadas a ordenar un espacio jurídico en el que los puntos de referencia se han vuelto cada vez más borrosos. El primer efecto derivado de tales actuaciones será el incremento de la segmentación del colectivo de trabajadores ya previamente segmentado en función de la duración y dedicación prevista en su contrato, de los distintos operadores movilizados en él, etc. En este sentido, las medidas que aquí estamos analizando se inscribirían en la genealogía de las transformaciones categoriales estudiadas desde finales de la década de 1970 a raíz de las sucesivas crisis que han conocido los países industrializados (Maurin y Dauty, 1992; Puel, 1980). Estas medidas vendrían a complejizar un laberinto ya de por sí complejo de situaciones de trabajo delimitadas por el derecho y donde la denominada norma de empleo estándar va progresivamente desfigurándose.

Más allá de la evanescencia de dicha norma de empleo -cuya existencia fue, en realidad, bastante más breve y menos "gloriosa" de lo que solemos presuponer (Pessis, Topçu y Bonneuil, 2013)-, la constante proliferación de nuevas categorías del derecho termina por invisibilizar los rasgos fundamentales que comparten todos estos trabajadores. Como anticipábamos previamente, autónomos o asalariados, al margen de su forma concreta de empleo, todos ellos trabajan, es decir, se inscriben en un dispositivo mercantil cuyos fines desbordan los suyos propios y gracias al cual acceden a los intercambios sociales. Reconocer este estatuto fundamental compartido por todo trabajador (autónomo o asalariado), cambia radicalmente el marco temporal de la reflexión reenviándola al ámbito del salariado, es decir, a una temporalidad donde el trabajo se muestra como tal, diferente a otras actividades sociales, y donde los intercambios entre agentes son de carácter puntual y azaroso. En el salariado el principal estatuto social adscrito a los trabajadores es el que se deriva de su empleo, si bien su vinculación a tal estatuto dura lo que dura la ocupación por parte del trabajador de dicho empleo. Los colectivos de trabajadores son así radicalmente diferenciados de los colectivos de consumidores, hasta el punto de que a menudo nuestros intereses como consumidores contradicen nuestros intereses como productores. En las sociedades salariales, sin embargo, la subordinación no se circunscribe a la posición ocupada por el asalariado en tanto que trabajador. Dicha posición constituye, sin duda, un momento fundamental donde se explicita su dependencia primigenia, pero se trata de una dependencia que el trabajador arrastra consigo a las más diversas situaciones (aprendizaje, formas de empleo, desempleo) y que le permite integrarse en un dispositivo productivo donde su capacidad de trabajo actúa a modo de recurso movilizable e intercambiable.

La proliferación de categorías jurídicas distorsiona, sin duda, ese espacio común fundamental que existe entre todas ellas pero, lógicamente, no radica ahí su principal razón de ser. Esta efervescencia categorial en realidad pone en evidencia la intervención del Estado en una cada vez más compleja labor de emparejamiento (temporal y bajo condiciones siempre cambiantes) de trabajadores y empleos. Así pues, la cons- 
trucción de estatutos de empleo híbridos, a medio camino entre el trabajo asalariado y el trabajo autónomo, debería ser enmarcada dentro de la acción pública en materia de empleo. Una actuación mediante la cual los Estados sostienen a los mercados, aligeran las cargas de trabajo, reciclan y seleccionan la mano de obra según diferentes criterios, incitándoles a la inserción o, por el contrario, al abandono. El trabajo autónomo no es, en este sentido, un objeto novedoso en los dos países que estamos analizando. En ambos casos, el interés por el trabajo autónomo tomó inicialmente la forma de medidas de lucha contra el desempleo, convirtiendo a los parados en emprendedores mediante la conversión de sus prestaciones por desempleo (percibidas en un único pago) en capital inicial. En Francia, esta historia arranca en 1979 con la creación del primer dispositivo de incitación a la creación de empresas (Ayuda a los Parados Creadores y Continuadores de Empresas, ACCRE en su acrónimo francés), un instrumento que se ha ido activando o desactivando en función de la coyuntura. Dicho dispositivo ha sido, posteriormente, complementado por otros dotados de objetivos similares $^{6}$. El caso español es un poco más tardío, pero arranca con una iniciativa de espíritu muy similar al ACCRE francés. Una iniciativa (Ministerio de Trabajo y Seguridad Social, 1985) que posibilitaba también a los desempleados españoles capitalizar su prestación por desempleo para establecer un negocio propio, tras la cual se multiplicarán los dispositivos orientados a poblaciones específicas ${ }^{7}$.

En ambos recorridos, los respectivos Estados han tolerado regímenes de trabajo enormemente inciertos desde un punto de vista jurídico. Sin embargo, el régimen AE y la LETA marcan, en este sentido, un importante punto de inflexión. Dichas formalizaciones no se limitan (únicamente) a una reformulación de las medidas de apoyo a los desempleados, sino que representan una actuación estatal de mayor calado que redefine las condiciones de ejercicio del trabajo autónomo y supone una intervención más general en materia de empleo. Ambos dispositivos se orientan, de hecho, al conjunto de la población activa (asalariada o autónoma o bajo una combinación de ambos estatutos) y no sólo a determinadas poblaciones específicas. Mediante la formalización de diferentes estatutos de empresa y el establecimiento de reglas de fiscalidad que les hacen más o menos atractivos y accesibles, las reformas implementadas incitan al trabajador que participa en el dispositivo mercantil del salariado a adoptar un rol más activo, contribuyendo a dicho dispositivo mercantil como responsable formal de una unidad económica más o menos real e independiente.

La participación de los Estados en una deriva de estas características llama por sí misma la atención, pero lo hace también con motivo de las sensibilidades ideológicas movilizadas. La figura del emprendedor condensa, como sabemos, las oposiciones ideológicas existentes entre la derecha y la izquierda del espectro político.

Los denominados agrupamientos de empleadores (1985), el porte salarial (finales de 1980), los Fondos de Garantía General para la Iniciativa de las Mujeres (1989), las incubadoras de actividades y empresas (1993), las cooperativas de actividades y de empleo (1995), el programa Apoyo a la Creación de Nuevas Empresas (EDEN) (1999), reemplazado en 2008 por el Nuevo Acompañamiento Para la Creación o Continuación de Empresas (NACRE), el Contrato de Apoyo al Proyecto de Empresa (CAPE) (2003), etc. hasta llegar al actual régimen del auto-emprendedor (2009).

El Plan de Promoción del Empleo Autónomo (Ministerio de Trabajo y Seguridad Social, 1986), el programa Emprender en Femenino (Ministerio de Trabajo y Asuntos Sociales, 1996), las distintas medidas urgentes para fomentar el empleo autónomo y la contratación (Ministerio de la Presidencia, 2008; Ministerio de Trabajo e Inmigración, 2009; Jefatura de Estado, 2009b y 2011), la Estrategia Española por el Empleo 2012-2014 (Ministerio de Trabajo e Inmigración, 2011b) o la conocida como Ley de Fomento del Trabajo Autónomo (Jefatura de Estado, 2015). 
Si bien presuponemos que dicha figura será promovida por la primera, no deja de extrañarnos que ocurra en ocasiones lo mismo en el caso de la segunda. Sin embargo, en España, la iniciativa que aquí estamos analizando hay que vincularla al gobierno socialista de Rodríguez Zapatero (2004-2011) el cual, apenas llegado al poder, convocó a un grupo de expertos (cuatro juristas expertos en derecho del trabajo y un economista) para la redacción del anteproyecto de la LETA. Del mismo modo, cuando la izquierda vuelve al poder en Francia en 2012 no pondrá en cuestión ni el régimen AE, ni las disposiciones generales de la Ley de Modernización de la Economía (LME), a la que se había opuesto como oposición ${ }^{8}$. Sobre el papel, sin embargo, las concepciones que ambas opciones políticas tienen sobre la figura del emprendedor no tienen nada que ver entre sí. Para la derecha el emprendedor encarnaría la potencia creadora liberada del peso de lo social y capaz de innovar frente a los riesgos, una especie de emprendedor schumpeteriano (Schumpeter, 1935). La izquierda, por su parte, ha solido desconfiar en gran medida de dicha figura, denunciando la fragilidad de lo que considera trabajadores aislados que, más allá de su aparente libertad, se encontrarían atrapados bajo subordinaciones económicas de diverso tipo. Las alternancias políticas registradas en ambos países han sido motivo, de hecho, de pequeños desplazamientos esperables. La izquierda española, por ejemplo, ha considerado al "nuevo" autónomo como un trabajador al que habría que proteger, mientras que la derecha, una vez de nuevo en el poder, ha tendido a concebirle como un "emprendedor" al que liberar. En Francia, si bien los socialistas han asumido, tal y como hemos señalado, las disposiciones de la LME sin modificar apenas su fundamento, el énfasis se ha desplazado, sin embargo, hacia la constitución de un tejido productivo más flexible, innovador y creador de empleo. El auto-emprendedor no ocupa ya el centro de la estrategia económica socialista, sino que dicha centralidad es ahora reservada a las unidades económicas con mayor potencial de creación de empleo: las denominadas "empresas de tamaño intermedio", categoría de muy reciente creación considerada como decisiva para la creación de riqueza.

Las diferentes lecturas del emprendizaje operadas por el poder político no son inocuas respecto a la aplicación de medidas como las que estamos analizando, por lo que no se trata de una cuestión meramente anecdótica. España y Francia han sido testigos, sin embargo, de una continuidad llamativa en los dispositivos implementados más allá de que las alternancias políticas hayan llevado a "interpretarlos" de forma diferenciada. Tales dispositivos son siempre presentados como necesarios, integrados en el discurso de la modernización de la economía, de la estimulación de la creación de valor, del empleo, de la innovación o de la prosperidad económica. Las propias instancias europeas no son ajenas a este tipo de justificaciones, tal y como demuestra el hecho de hacer del trabajo autónomo y del emprendimiento uno de los principales ejes de la Estrategia Europa 2020 (European Commission, 2010).

Dicha ley será aprobada en Francia por el 58\% de los votos del Parlamento (321 a favor y 230 en contra). La LETA, por su parte, fue aprobada por unanimidad en el Parlamento español. 


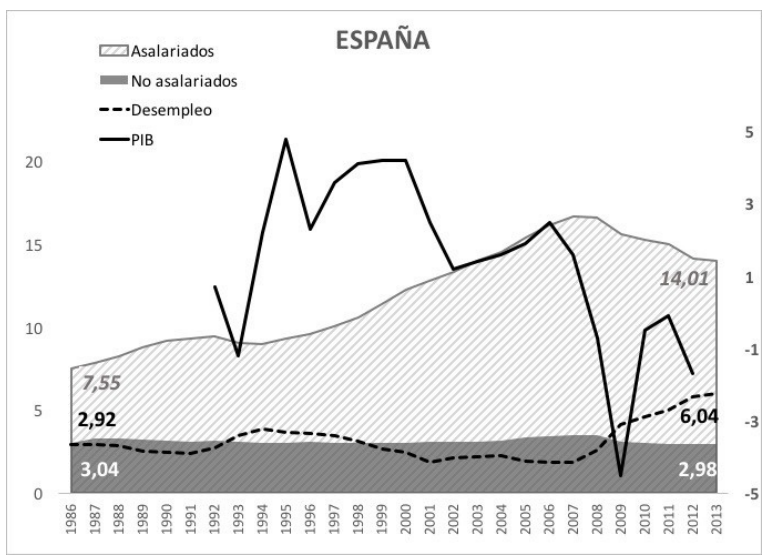

Gráfico 1. Evolución del trabajo por cuenta propia, del trabajo asalariado, del número de desempleados (eje de la izquierda) y del PIB en España (eje de la derecha) entre 1986 y 2013

Fuente: Eurostat. PIB: variación porcentual con respecto al año anterior. Asalariados, cuenta propia y desempleados: número medio anual (15-64 años) en millones.

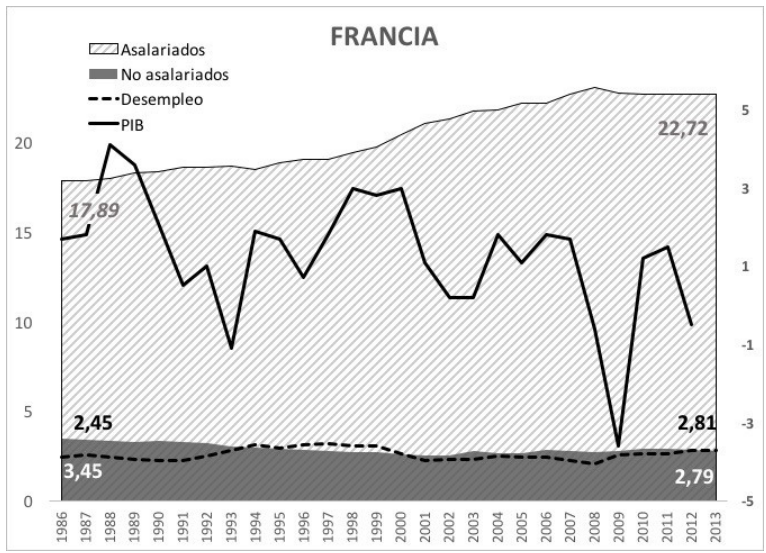

Gráfico 2. Evolución del trabajo por cuenta propia, del trabajo asalariado, del número de desempleados (eje de la izquierda) y del PIB en España (eje de la derecha) entre 1986 y 2013.

Fuente: Eurostat. PIB: variación porcentual con respecto al año anterior. Asalariados, cuenta propia y desempleados: número medio anual (15-64 años) en millones.

La comparación entre España y Francia muestra a este respecto que las reformas analizadas se han ido desplegando, de hecho, durante fases de expansión económica más que de recesión (Gráficos 1 y 2). La LETA se elaboró antes de la crisis financiera del verano de 2007 y el régimen EA antes de que dicha crisis afectara de forma más profunda a la economía francesa a lo largo de 2009. La creación y puesta en marcha de ambos estatutos se ha efectuado pues en un contexto en el que, pese a la existencia de altibajos (en particular entre 2003-2005), el crecimiento económico se ha mantenido constante en ambos países desde la crisis de los años 1992-1993, 
llegando a ser incluso destacable en el caso de España, con un crecimiento medio del PIB superior al de la zona Euro (3,8\%, con máximos del 5\%, frente al 2,3\% de la zona Euro) (Eurostat). Las tasas de paro se mantuvieron igualmente a la baja durante este periodo -un 8\% en 2007 en el caso de España y el 7\% en Francia (Eurostat)-, al tiempo que la población activa registraba un claro crecimiento (también aquí mucho más espectacular en el caso español donde prácticamente se duplicó entre 1976 y 2007) (INSEE, INE).

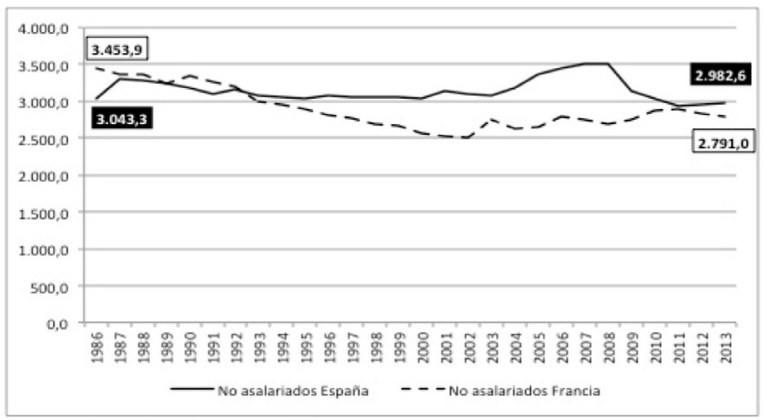

Gráfico 3. Evolución del trabajo no asalariado en Francia y España entre 1986 y 2013. Número de trabajadores no asalariados (entre 15-64 años) por año.

Fuente: Eurostat. Unidades: Miles.

La comparación entre ambos países muestra también que estos casi diez años de crecimiento han conocido la estabilización, cuando no incremento, del trabajo autónomo después de un movimiento histórico de repliegue en favor del trabajo asalariado resultado de las mutaciones socio-económicas de la postguerra (Gráfico 3). Ambos dispositivos se preparan pues en un momento en el que el trabajo autónomo al que tratan de reorganizar se encuentra ya en plena transformación. La actuación del Estado en ambos casos habría servido de acompañamiento a una dinámica desencadenada previamente, una dinámica que ellos contribuyen sin duda a alimentar pero que no son sus iniciadores. Dicho de otro modo, la reorganización que supone la LETA en España no ha sido una "invención" del Gobierno socialista, del mismo modo que el éxito que ha registrado en Francia el régimen EA se debe en gran medida a que los auto-emprendedores ya existían previamente. Aunque los Estados son, sin lugar a dudas, un actor activo en el proceso de hibridación de las formas de movilización de la fuerza de trabajo, su actuación y regulación resulta sin embargo confusa. Nos encontramos lejos del tipo de actuación enérgica implementada en Europa por las élites dirigentes tras la Segunda Guerra Mundial mediante la movilización de una ideología del progreso sin fisuras (Pessis, Topçu y Bonneuil, 2013). Es posible, por lo tanto, que los Estados contemporáneos se hayan (más o menos) plegado a las virtudes neoliberales (Abdelnour, 2014) pero reducir el análisis únicamente a su componente ideológico deja fuera muchas otras preguntas interesantes. 


\section{Un proceso de reforma ambiguo}

El análisis comparativo de las nuevas formalizaciones registradas en materia de trabajo autónomo requiere ser enmarcado dentro de dos estrategias reformistas a priori diferenciadas (cf. anexo). La primera de las estrategias, presente en el caso español (Riesco-Sanz, 2016), reconoce las situaciones de dependencia económica del trabajo autónomo mediante la creación de la figura de los denominados trabajadores autónomos económicamente dependientes (o TRADE): aquellos que al menos el 75\% de sus ingresos de trabajo dependen únicamente de un tercero (ya sea persona física o jurídica) denominado cliente. La aprobación de la LETA ha supuesto igualmente la introducción de una definición positiva de la categoría genérica de trabajo autónomo, ya no considerado simplemente como aquello que no es trabajo asalariado, sino definido a partir de tres condiciones fundamentales que deben darse de forma simultánea: la actividad de los trabajadores debe ser explícitamente económica -es decir, orientada a la obtención de un beneficio-, regular y autónoma en lo que se refiere a su dirección y organización. La pérdida o ausencia de alguno de estos criterios imposibilitaría el acceso a este nuevo estatuto de empleo.

Francia, por su parte, encarna la segunda vía reformista consistente en una redefinición del contrato regulado por el derecho privado que no genera nuevas instancias jurídicas situadas a medio camino entre dicho tipo de contrato y el espacio regulado por el contrato de trabajo. La vía reformista desarrollada en Francia concibe a los trabajadores autónomos del nuevo estatuto AE como emprendedores y les aplica una versión simplificada del régimen económico de la micro-empresa (denominado aún régimen micro-social). Los auto-emprendedores son micro-emprendedores particulares en tanto en cuanto se embarcan solos, como personas físicas, en una actividad económica por cuenta propia que puede ser ejercida como actividad principal o complementaria $^{9}$. La posibilidad de acumular distintos estatutos de empleo no es nueva en Francia y ya existía, por ejemplo, en figuras como la del "emprendedor-asalariado" de las cooperativas de actividad y empleo (Darbus, 2008). Lo que hace el régimen $\mathrm{AE}$ es estabilizar jurídicamente dicho estatuto al tiempo que lo promueve, simplificando los procedimientos requeridos para la creación de empresas o estableciendo cotizaciones sociales ventajosas.

A ambos lados de los Pirineos surgen pues nuevos trabajadores y nuevos emprendedores como respuesta a las dificultades derivadas del incremento del número de trabajadores sujetos a estatutos de empleo inciertos. La respuesta española al problema ha encontrado en Francia, en términos generales, una acogida favorable (Triomphe, 2008) debido a la mayor protección que ofrece a través de figuras como los TRADE. Dentro del trabajo autónomo europeo, los trabajadores TRADE españoles han sido percibidos como los mejor protegidos frente a las incertidumbres de los mercados o, dicho de otro modo, como los autónomos con una situación más próxima a la de los asalariados. Sin embargo, ¿son realmente así las cosas? ¿Nos encontramos en verdad ante dos reformas tan diferentes? Semánticamente las diferencias son a menudo sutiles: los nuevos trabajadores autónomos españoles deben consagrarse

Las cifras de inscripciones totales en el régimen AE fueron de 217.000 en 2009 y 360.000 en 2010 (INSEE), un incremento que señala el éxito inmediato registrado por dicho régimen. Un tercio de las inscripciones registradas fueron efectuadas por asalariados del sector público o privado, jubilados y estudiantes que encontraron en este nuevo estatuto un medio para incrementar sus ingresos (Barruel, Thomas y Filatriau, 2014). 
a una actividad económica que presenta muchos rasgos propios del empresariado, mientras que los nuevos emprendedores franceses son, en gran medida, asalariados o antiguos asalariados. La confusión se acentúa cuando prestamos atención a los derechos y protecciones adscritos a dichos estatutos. Aunque detrás de ambos tipos de regulaciones podríamos intuir la preocupación de los Estados por la pérdida de cotizaciones e impuestos que se derivaría del trabajo ilegal, lo cierto es que ambos dispositivos tratan de conceder prerrogativas a trabajadores cuya situación legal de agentes económicos "independientes" no les garantiza.

Estas prerrogativas y protecciones se encuentran organizadas en España por medio de un acercamiento entre el trabajo autónomo y el trabajo asalariado, aun cuando tal aproximación sea todavía incompleta ${ }^{10}$. La LETA ha instituido para los trabajadores autónomos algunos derechos fundamentales típicos del trabajo asalariado como el derecho de asociación, representación y defensa de los intereses profesionales, el permiso de maternidad/paternidad... (cf. anexo). La proximidad con respecto a los asalariados es aún más evidente en el caso de la subcategoría TRADE, principal novedad de la LETA cuyo éxito ha sido, no obstante, limitado ${ }^{11}$. Entre los derechos acordados a los TRADE nos encontramos con algunas de las características fundamentales de los contratos de prestación de servicios convencionales, como por ejemplo: la obligación de firmar por escrito un contrato de trabajo específico; el reconocimiento del derecho a una prestación por desempleo; la mejora de la protección frente a los riesgos profesionales; la implementación de una especie de negociación colectiva "light" sobre las condiciones de trabajo que podría desembocar en la firma de "acuerdos de interés profesional" de aplicación en las empresas donde se realiza la prestación de trabajo; o, finalmente, el reconocimiento de la jurisdicción de lo Social (propia del trabajo asalariado) como la competente para resolver los posibles conflictos entre autónomos TRADE y sus empleadores.

¿Cuáles serían entonces las diferencias entre los autónomos TRADE y los asalariados españoles? Desde el punto de vista de la actividad, los primeros disponen de una autonomía (formal) en la organización de su jornada de trabajo y en la posibilidad de contratar un $25 \%$ de su actividad con otros clientes diferentes. Se diferencian también, y es algo importante, por su sistema fiscal de referencia y, sobre todo, por su régimen de Seguridad Social. En términos generales, como sabemos, los trabajadores autónomos se encuentran adscritos al Régimen Especial del Trabajo Autónomo (RETA). Un régimen creado en 1970 que, a pesar de las transformaciones registradas, sigue caracterizándose por bajas cotizaciones y, en consecuencia, también por menores prestaciones y mecanismos de protección que los existentes para los asalariados $^{12}$. El acercamiento entre la figura de los TRADE y la población asalariada no se ha traducido en una equiparación real de derechos entre trabajadores autónomos y

10 A pesar del esfuerzo realizado, las diferencias persisten entre un estatuto y otro. En lo que se refiere a la prestación por jubilación, por ejemplo, las cantidades percibidas por los trabajadores autónomos a través de la Seguridad Social son aún reducidas y muy inferiores (el 38\%) a las del Régimen General donde se integra el grueso de los asalariados (Unión de Profesionales y Trabajadores Autónomos, 2012).

11 Según los datos de afiliación a la Seguridad Social del Ministerio de Empleo y Seguridad Social, a 31 de diciembre 2015 había 9.851 contratos TRADE registrados cuando diferentes estudios (Agut y Nuñez, 2012; Asociación de Trabajadores Autónomos, 2006) han estimado en unos 300.000 (alrededor del 14\% del total de autónomos) los trabajadores autónomos que podrían potencialmente formar parte de dicho colectivo.

12 De los algo más de 3 millones de autónomos registrados en el RETA a 31 de diciembre de 2015, el 67,3\% cotizaba con las bases mínimas de la Seguridad Social (884,40 €) (Ministerio de Empleo y Seguridad Social, 2016). 
asalariados, observación que es igualmente válida en lo que se refiere a la protección frente al desempleo ${ }^{13}$; o a los mecanismos de "negociación colectiva" previstos por la LETA cuya eficacia ha sido puesta en cuestión por algunos investigadores (Castro, 2011; Cairós, 2008; Aparicio et al. 2007).

La legislación española se encarga, por lo tanto, de organizar la externalización fuera de la empresa de tareas parciales del sistema productivo, canalizando el grueso de la actividad de una colectividad de trabajadores determinada. Unos trabajadores -desvinculados formalmente de la empresa y definidos como autónomos- que contratan sus servicios con clientes que son en realidad los ordenantes de su actividad. $\mathrm{Su}$ subordinación no resulta tan directa como en la empresa, donde la actividad es dirigida y coordinada con la del resto de empleados por medio de la autoridad directa del empleador o de las personas en las que éste delegue, pero no deja de ser una subordinación de carácter económico. En el caso español, el Estado interviene facilitando a los agentes implicados un marco regulador mínimo para sus intercambios, concediendo al mismo tiempo algunos derechos, generosos sobre el papel, más restringidos si analizamos la realidad empírica de la aplicación del régimen del trabajo autónomo. La perdurabilidad en el tiempo de la actividad se concibe como un asunto responsabilidad del trabajador autónomo. Su "cliente" permanece ajeno a la obligación de subvencionar las posibles rupturas que él mismo pueda ocasionar en tal continuidad, siendo la colectividad de trabajadores autónomos la que deberá hacerse finalmente cargo a un coste (y protección) menor que el de los asalariados. A la espera de un examen más minucioso, podemos por ahora limitarnos a señalar que el modelo español ejemplifica, sobre todo, la extensión de un modo singular de gestión de una mano de obra externalizada a la que, mal que bien, se dota de ciertos derechos sociales.

El modelo francés, por su parte, reconoce al auto-emprendedor por la actividad económica que genera, actividad que el derecho identifica como "empresa" y por la cual es denominado emprendedor. El auto-emprendedor no es pues, a priori, un asalariado. No obstante, si se observa con atención, veremos que estamos ante un emprendedor bastante singular. Para empezar, como ya hemos mencionado, puede ser un asalariado y acumular distintos estatutos sin perder ninguna de las ventajas de su estatuto inicial: las rentas obtenidas por un tercio de los AE son consideradas como recursos complementarios y, desde ese punto de vista, están sujetas a los impuestos y cotizaciones sociales aplicables a su fuente principal de renta (salario o pensión) (Omalek y Rioux, 2015). Aquellos cuya actividad como autónomos sí constituye su actividad principal cotizan en cambio en el denominado Régime Social des Indépendants (RSI), donde se integran también los autónomos "tradicionales" (artesanos, comerciantes y profesiones liberales). En dicho régimen se benefician de cotizaciones fijas y de procedimientos simplificados que les garantizan derechos sociales relativamente favorables, aunque con prestaciones algo inferiores a las de los asalariados (si bien la tendencia apunta a una cierta equiparación). Desde el punto de vista (fundamental) de las protecciones sociales, los auto-emprendedores no pueden ser, por

13 En relación a esta protección (obligatoria para los TRADE, voluntaria para el resto de los autónomos), los datos de 2012 -referidos al conjunto de los trabajadores autónomos y no únicamente a los denominados TRADE- señalan que únicamente el $21 \%$ de los trabajadores autónomos inscritos en la Seguridad Social estaban asegurados ante el cese de actividad (Unión de Profesionales y Trabajadores Autónomos, 2012), frente al 38\% de cobertura del conjunto de la población activa (el 78\% si no consideramos únicamente las prestaciones contributivas por desempleo) (Instituto Nacional de Estadística, Indicadores Sociales, 2011). 
lo tanto, simplemente considerados como una especie de asalariados "fragilizados": al igual que los asalariados, los auto-emprendedores perciben remuneraciones -variables, cierto es, pero de idéntica naturaleza (financieras y sociales)- que preparan y organizan íntegramente su vida laboral (maternidad, jubilación, enfermedad...).

En lo que se refiere a la actividad económica cabe señalar que el régimen $\mathrm{AE}$, a diferencia de lo que ocurre con el estatuto del trabajo autónomo español, no reconoce situaciones de dependencia económica que doten a los trabajadores de protecciones ampliadas. Conviene, no obstante, recordar a este respecto la intensa actividad jurídica registrada en Francia mediante la cual los jueces redefinen a menudo como asalariadas situaciones concebidas a priori como autónomas, rectificando y tratando de compensar así lo que consideran como una subordinación abusiva y sin contrapartidas. Los auto-emprendedores franceses carecen, no obstante, de prestación por desempleo y deben asegurarse por su propia cuenta ante las consecuencias derivadas del cese de actividad. Dicha carencia es, sin embargo, lógica, si tenemos en cuenta el espíritu de la ley que regula su actividad: la exposición de motivos de la ley de modernización de la economía (LME) señala claramente el carácter provisional que se desea otorgar a este nuevo estatuto. Dicha declaración de intenciones insiste igualmente en tres objetivos: promover y facilitar la incorporación al trabajo autónomo (jugando aquí un papel fundamental la complementariedad de estatutos); reducir los riesgos económicos, patrimoniales y sociales vinculados a tales actividades; $y$ facilitar cuanto sea posible los movimientos entre unos y otros estatutos a lo largo de la vida profesional del trabajador (posibilitando incursiones muy breves en el trabajo autónomo).

Aunque puedan existir situaciones reales de "auto-emprendimiento", parece evidente que el régimen $\mathrm{AE}$ ha sido concebido como un estatuto de transición entre el trabajo autónomo y el trabajo asalariado. Un régimen que trata de favorecer la complementariedad y circulación entre estatutos minimizando el coste de transitar entre ellos, al tiempo que protege las experimentaciones emprendedoras de los asalariados (como también ocurre, de hecho, en las medidas recientemente aprobadas en España) (Jefatura de Estado, 2015). Ggarantía para el acceso o mantenimiento de los derechos sociales, el estatuto AE en Francia - un estatuto marcado por la complementariedad y su capacidad de transferencia- más que una precarización directa impulsaría una cierta homogeneización del trabajo autónomo y del trabajo asalariado en lo que se refiere a los derechos sociales.

\section{A modo de conclusión}

España y Francia han impulsado dispositivos jurídicos que, mediante dos caminos a priori diferenciados, instauran un mismo estatuto paradójico de independiente-dependiente. España ha inscrito la dependencia económica de una parte de los autónomos en la propia ley, mientras que Francia ha organizado de manera más amplia la confluencia de dos estatutos que el derecho se había encargado hasta entonces de diferenciar. Tales reformas responden a una dinámica, perceptible desde comienzos de siglo, tendente a crear empleos dotados de estatutos inciertos, situados en la frontera entre el empleo asalariado y el autónomo. No se trata de que tales modalidades de empleo sean necesariamente ilegales: el recurso al emprendizaje como medida de lucha contra el desempleo ha dado lugar en ambos países a experimentaciones re- 
currentes, algunas de ellas lo suficientemente extensas como para que tales empleos sean hoy posibles y tolerados. Su extensión reclama, sin embargo, configuraciones institucionales más robustas, concretamente desde el punto de vista de unas prerrogativas y protecciones que la situación formal de estos trabajadores (como actores económicos "independientes") no les confiere. Los estatutos TRADE y AE proporcionan derechos al tiempo que se mantiene su actividad económica bajo el signo del "libre intercambio". Unos derechos variables según los países y dotados de mayor o menor eficacia según los casos, pero que tienen en común su vinculación a un mismo modelo salarial con el cual se comparan y articulan, un modelo cuyas instituciones protegen a los individuos contra los riesgos sociales y gestionan el conjunto de su vida laboral.

Desde esta perspectiva, resulta complicado reducir los nuevos dispositivos analizados a una mera iniciativa de desmantelamiento del salariado. Desde un punto de vista lógico asistimos más bien a una nueva extensión del mismo o, para ser más precisos, a una atenuación (cuando no un ocultamiento) de las ambigüedades presentes en los respectivos derechos del trabajo nacionales cruciales para su regulación. Unos derechos del trabajo que hasta ahora han circunscrito la subordinación de los trabajadores al contrato asalariado, disimulando tal subordinación bajo las contrapartidas sociales acordadas en él y sin prestar atención a las subordinaciones existentes más allá del contrato. Los Estados se preocupan por tales subordinaciones ignoradas e, incluso, tal y como hemos visto, las organizan. Sin duda responden así a necesidades que podríamos considerar como eminentemente políticas, pero también prácticas pues, de una u otra manera, resulta necesario que estos trabajadores participen en la gestión, hoy por hoy colectiva, de la fuerza de trabajo y de su renovación, que el propio colectivo se dote de los recursos necesarios para afrontar sus necesidades crecientes. Dicho reto, tal y como pone en evidencia la comparación efectuada entre ambos países, es percibido por todos los actores, con independencia de su orientación política.

Las respuestas estatales que hemos analizado permiten a los trabajadores hibridos acceder a derechos propios de los asalariados, "privilegios" obtenidos previamente por estos en tanto que miembros de empresas. Sin embargo, en ambos países dicho acceso se realiza bajo condiciones que generan posiciones sociales circunstanciales, salpicadas de umbrales y de criterios que encuadran la actividad y los derechos de estos trabajadores. Tal conjunto de reglas es revisable en todo momento por parte del poder público, potenciando a los candidatos cuando los requisitos se flexibilizan, desmotivándoles cuando se endurecen. Situado al margen de la autoridad de la empresa, nos encontramos con un trabajador autónomo que depende, no obstante, de las normas y juicios de un organismo colectivo con múltiples cabezas, discrecional y que actúa según lógicas y bajo circunstancias diversas. Sin embargo, esta actuación del poder público registra importantes limitaciones como consecuencia de las contradicciones que suscita. Por ejemplo, el ahorro en las cotizaciones a los seguros sociales que obtienen los empleadores individuales por medio de estos nuevos estatutos ¿cómo financiarlo si no es de manera indirecta vía impuestos? Del mismo modo ¿hasta dónde pueden tolerar los Estados la actividad sin cortapisas de estos trabajadores autónomos en los márgenes de profesiones altamente reglamentadas? $\mathrm{O}$ ¿de qué manera podrán los organismos gestores de los derechos sociales de los autónomos absorber el coste de integrar a unos nuevos beneficiarios -en su mayoría- escasamente contribuyentes? 
En resumen, estos nuevos estatutos de empleo modifican el escenario al tiempo que apuntalan muchas transformaciones previamente existentes. Si bien en ambos países los Estados se han puesto claramente manos a la obra, su actuación ha sido, no obstante, dubitativa y oscilante en función de los problemas registrados: en Francia, por ejemplo, la denuncia de competencia desleal, así como las críticas a unas cotizaciones consideradas como excesivamente elevadas por parte de los "autónomos tradicionales"; en España el escaso éxito registrado por algunas de las medidas estrella del nuevo estatuto como la formalización jurídica de los autónomos dependientes o la puesta en marcha de un sistema voluntario de protección por cese de actividad. La regulación llevada a cabo por estos Estados podría también ser leída, qué duda cabe, como una desregulación. En cualquiera de los casos, sus acciones resultan en gran medida confusas, más allá de la aparente claridad de sus motivaciones. Los nuevos dispositivos jurídicos aquí analizados, respondiendo a las ambigüedades del derecho, abren desde nuestro punto de vista la posibilidad de nuevas formas de desvinculación de los trabajadores con respecto a la empresa. Los trabajadores pueden así contribuir al proceso productivo del que participa la empresa manteniéndose, sin embargo, en su periferia o conformando incluso una actividad productiva propia relativamente perenne. Si la hipótesis es correcta, las situaciones de trabajo que acabamos de observar están llamadas a multiplicarse y exigirán soluciones jurídicas más radicales que los ambiguos procedimientos hoy por hoy implementados. Su examen deberá pues continuarse, ya no únicamente bajo el ángulo exclusivo de la acción pública, tal y como aquí hemos efectuado, sino bajo el de la dinámica productiva y las concomitantes transformaciones de la empresa.

\section{Bibliografía}

Abdelbour, S. (2014) "L'auto-entrepreneuriat: l'indépendance comme modalité d'embauche ?". En Célérier, S. Le travail indépendant : Statut, activités et santé (pp. 69-91). París: Éditions Liaisons-Wolters Kluger,.

Agut, C. y Núñez, C. (2012) La regulación del trabajo autónomo económicamente dependiente en España: un análisis crítico comparado con Italia. Working paper 124. Associazione per gli Studi Internazionali e Comparati sul Diritto del Lavoro e sulle Relazioni Industrialli.

Aparicio, J. et al. (2007) "Editorial". Revista de Derecho Social 39 : 2-8

Asociación de Trabajadores Autónomos (2006) Informe del trabajo autónomo dependiente. (http://www.ata.es).

Barruel, F.; Thomas, S. y Filatriau, O. (2014) “Créateurs d'entreprises : avec l'auto-entreprenariat, de nouveaux profils". Insee première 1487: 1-4.

Berton, F.; Pacelli L. y Segre, G. (2005) "Il Lavoro Parasubordinato in Italia. Tra Autonomia Del Lavoratore e Precarietà del Lavoro". Rivista Italiana degli Economisti 10: 57-99.

Böheim, R. y Mühlberger, U. (2009) "Dependent self-employment: workers between employment and self-employment in the UK". Journal for Labour Market Research 42: 182-195.

Bureau, M.-C. y Corsani, A. (2012) Un salariat au-delà du salariat? . Nancy: Éditions Univ. de Lorraine.

Cairós, D. (2008) "Acerca de la denominada crisis del contrato de trabajo tradicional y la aportación española: el estatuto del trabajo autónomo”. Gaceta Laboral 14 (2): 193-219. 
Castro, M.A. (2011) "Los Acuerdos de Interés Profesional: un balance de la negociación llevada a cabo al amparo del Estatuto del Trabajo Autónomo". Anales de derecho 29: 34-80.

Célérier, S. (2012) "Le salariat dans la chair ou les ambivalences du tâcheronnat dans les industries de viandes de volaille". En Cingolani, P. (dir.), Un travail sans limite? (pp. 82-100). París: Eres.

D’Amours, M. (2014) Nouvelles formes d'emploi, représentation collective et régimes alternatifs de rapports collectifs de travail. Montreal: Université Laval.

Darbus, F. (2008) “L'accompagnement à la création d'entreprise". Actes de la recherche en sciences sociales, 175 (5): 18-33.

European Commission (2010) Europe 2020. A strategy for smart, sustainable and inclusive growth. [COM(2010)2020]. Bruselas: European Commission.

Gaudu, F. (1986) L'emploi dans l'entreprise privée : essai de théorie juridique. Tesis doctoral defendida en la Université de Paris 1, París.

Jefatura del Estado (2007) “Ley 20/2007, de 11 julio”. BOE, 166: 29964-29978.

(2009) "Real decreto-ley 2/2009", de 6 de marzo. BOE, 57: 23276-23284.

(2010) "Ley 32/2010, de 5 de agosto". BOE, 190: 68526-68551.

(2011) "Real decreto-ley 3/2011, de 18 de febrero". BOE, 43: 19240-19260.

(2014) "Ley 35/2014, de 26 de diciembre". BOE, 314: 105960-105995.

(2015) "Ley 31/2015, de 9 de septiembre". BOE, 217: 79824-79848.

Maurin, M.-L. y Dauty, F. (1992) "Entre le travail et l'emploi : la polyvalence des contrats à durée déterminée". Travail et Emploi 52: 20-36.

Ministerio de Empleo y Seguridad Social (2016) “Trabajadores autónomos, personas físicas en alta en la Seguridad Social, 31 de diciembre de 2015”. http://www.empleo.gob.es [consulta 11 de abril de 2016].

Ministerio de Trabajo y Seguridad Social (1985) "Real Decreto 1044/1985, de 19 de junio". BOE, 157: 20695.

(1986) "Orden de 21 de febrero por la que se establecen diversos programas de apoyo a la creación de empleo”. BOE, 50: 7634-7636.

Ministerio de Trabajo y Asuntos Sociales (1996) "Orden de 28 de octubre de 1996". BOE, 269: 33977-33979.

Ministerio de la Presidencia (2008) "Real Decreto 1975/2008, de 28 de noviembre". BOE, 290: 48135-48142.

Ministerio de Trabajo e Inmigración (2009a) "Real Decreto 1997/2009, de 23 de febrero". BOE, 54: 22048-22062.

(2009b) "Real Decreto 1300/2009, de 31 de julio". BOE, 200: 71322-71327.

(2010) "Real Decreto 1613/2010, de 7 de diciembre“. BOE, 315: 107642-107653.

(2011a) "Real Decreto 1541/2011, de 31 de octubre". BOE, 263: 114289-114312.

(2011b) "Real decreto 1542/2011, de 31 de octubre". BOE, 279: 121069-121155.

Naville, P. (1984) La maîtrise du salariat. París: Anthropos.

Omalek, L. y Rioux, L. (2015) Emploi et revenus des indépendants. París: INSEE.

Perulli, A. (2003) Economically Dependent/Quasi-subordinate (Parasubordinate) Employment: Legal, Social and Economic Aspects. Bruselas: Comisión Europea.

Pessis, C.; Topçu, S. y Bonneuil, C. (2013) Une autre histoire des Trente Glorieuses : Modernisation, contestations et pollutions dans la France d'après-guerre. París: La Découverte.

Puel, H. (1980) "Il y a emploi et emploi", Travail et emploi 4: 17-23.

Riesco-Sanz, A. (2016) “Trabajo, independencia y subordinación. La regulación del trabajo autónomo en España”. Revista Internacional de Sociología, 74(1): e026. 
Rolle, P. (1988) Travail et salariat. Bilan de la sociologie du travail. Grenoble: Presses universitaires de Grenoble.

(1997) Où va le salariat? Lausanne: Page Deux.

Schumpeter, J.A. (1935) Théorie de l'évolution économique. Recherches sur le profit, le crédit, l'intérêt et le cycle de la conjoncture. París: Dalloz.

Triomphe, C.E. (2008) "L'essor du travail indépendant en Europe", presentación oral efectuada en la Direction régionale du travail, de l'emploi et de la formation professionnelle d'Ile de France, París, 23/09/2008.

Unión de Profesionales y Trabajadores Autónomos (2012) Anuarios del trabajo autónomo en España, 2011-2012. Madrid: Ministerio de empleo y seguridad social. 


\section{Anexo: resumen de los dispositivos jurídicos analizados}

\section{ESTATUTO DEL TRABAJADOR AUTÓNOMO ESPAÑOL (12/10/2007) $)^{14}$}

\section{Marco legal}

El Estatuto del Trabajador Autónomo (Jefatura de Estado, 2007) fue creado mediante la Ley 20/2007 de 28 de junio de 2007 (en vigor desde el 12 de octubre). Dicha ley ha conocido desde entonces diferentes reformas que han abordado la cuestión de los trabajadores autónomos económicamente dependientes y el registro de asociaciones de autónomos (Ministerio de Trabajo e Inmigración, 2009a), la representación del trabajo autónomo (Ministerio de Trabajo e Inmigración, 2010), la protección por cese de actividad (Jefatura de Estado, 2010; Ministerio de Trabajo e Inmigración, 2011a; Jefatura del Estado, 2014) o el fomento del trabajo autónomo (Jefatura de Estado, 2015).

\section{Condiciones de acceso y modalidades de salida}

El Estatuto se aplica de forma automática a todas las personas que realicen -de forma habitual, personal, directa, por cuenta propia y fuera del ámbito de dirección y organización de otra persona- una actividad económica o profesional de carácter lucrativo, con independencia de que contraten o no a otras personas. La pérdida o la no concurrencia de tales características suponen la exclusión del estatuto.

Los TRADE, por su parte, "realizan una actividad económica o profesional a título lucrativo y de forma habitual, personal, directa y predominante para una persona física o jurídica, denominada cliente, del que dependen económicamente por percibir de él, al menos, el 75\% de sus ingresos por rendimientos del trabajo y de actividades económicas o profesionales". Los TRADE están obligados a:

- Formalizar por escrito un contrato (depositado en el registro del Servicio Público de Empleo Estatal) entre el trabajador autónomo TRADE y su cliente en el que se identifique a las partes, se defina el objeto del contrato, el tiempo de trabajo y de descanso semanal y anual (con un mínimo de 18 días hábiles de vacaciones), o el "acuerdo de interés profesional" que eventualmente podría ser de aplicación (en caso de existir y de dar su consentimiento el trabajador).

- No emplear a trabajadores asalariados, ni subcontratar las actividades contratadas con el cliente.

- Ejecutar su trabajo de manera diferenciada del resto de trabajadores (asalariados o autónomos) contratados por el cliente.

- Disponer de su propia infraestructura productiva y de los materiales suficientes (independientes de los del cliente) para realizar la actividad solicitada.

- Desarrollar su actividad con criterios organizativos propios, más allá de las indicaciones técnicas que puedan recibir por parte del cliente.

- Percibir una contraprestación económica en función del resultado de su actividad y según los términos negociados previamente con el cliente, asumiendo en cualquier caso el riesgo económico de dicha actividad.

14 Síntesis efectuada a partir de la Guía Laboral (Ministerio de Empleo y Seguridad Social: http://www.empleo. gob.es/es/Guia/texto/guia_2/contenidos/guia_2_6_3.htm) 


\section{Derechos laborales}

- Derechos individuales a la igualdad y a la no discriminación; a la conciliación entre vida profesional y familiar; a la protección de los menores de 16 años y a la posibilidad de contratar como trabajadores asalariados de la empresa familiar a descendientes menores de 30 años; a la salud y la seguridad en el trabajo; a la prevención de los riesgos laborales; a garantías de carácter económico (duración del contrato, derecho a percibir una retribución a cambio de su actividad, protección de la vivienda principal del trabajador autónomo en caso de pérdidas financieras derivadas de su actividad profesional...).

- Derechos colectivos de asociación y defensa colectiva de los intereses profesionales; de participación en la definición y gestión de las políticas públicas que afecten al colectivo (reconocimiento de las asociaciones de trabajadores autónomos mayoritarias como interlocutores); creación del Consejo del Trabajo Autónomo (con presencia de organizaciones mayoritarias de autónomos, organizaciones sindicales, patronales y Administración Pública) como órgano de consulta y promoción del diálogo.

\section{Cobertura-protección social}

- Protección por enfermedad y maternidad, mayor cobertura para los riesgos profesionales de los TRADE.

- Derecho a la jubilación y a la prejubilación en caso de peligrosidad de la actividad (mayor cobertura en el caso de los TRADE).

- Prestación por cese de actividad (desempleo)

\section{Cotizaciones sociales}

\begin{tabular}{|c|c|c|}
\hline & $\begin{array}{l}\text { Base de cotización } 2016 \text { ( } \sin \\
\text { incluir excepciones) } € / \text { mes }\end{array}$ & $\begin{array}{l}\text { Cotizaciones (sin incluir las excepcio- } \\
\text { nes) }\end{array}$ \\
\hline $\begin{array}{l}\text { Régimen Especial } \\
\text { del Trabajo Autóno- } \\
\text { mo (RETA) }\end{array}$ & $\begin{array}{l}\text { Mínimo: } 893,1 \\
\text { Máximo: } 3.642\end{array}$ & $\begin{array}{l}29,8 \% \text { (con seguro por incapacidad } \\
\text { temporal/cese de actividad) } \\
26,5 \% \text { (sin seguro por incapacidad } \\
\text { temporal/cese de actividad) }\end{array}$ \\
\hline $\begin{array}{l}\text { Régimen General } \\
\text { (Trabajadores asala- } \\
\text { riados) }\end{array}$ & $\begin{array}{l}\text { Mínimo: } 764,4 \text { - 1.067,4 } \\
\text { Máximo: } 3.642\end{array}$ & $\begin{array}{l}28,3 \% \text { (contingencias comunes: } \\
23,6 \% \text { empresa; } 4,7 \% \text { trabajador) } \\
7,05 \% \text { (desempleo: } 5,5 \% \text { empresa; } \\
1,55 \% \text { trabajador) } \\
0,70 \% \text { (formación profesional: } 0,6 \% \\
\text { empresa; } 0,1 \% \text { trabajador) } \\
0,20 \% \text { (FOGASA) }\end{array}$ \\
\hline
\end{tabular}

\section{Medidas fiscales de apoyo al trabajo autónomo}

- Tarifa plana para nuevos autónomos en las cotizaciones a la Seguridad Social (50 € en lugar de los $267 €$ de media que se paga en cotizaciones con base mínima) durante los 6 primeros meses.

- Reducción de las retenciones del Impuesto de la Renta de Personas Físicas del $15 \%$ al $7 \%$ durante los 3 primeros años de actividad.

- Mantenimiento, aunque con restricciones mayores, de la tributación por módulos (mucho más ventajosa). 
- Reducciones en el impuesto de sociedades (en particular en las denominadas "Sociedades Laborales de Nueva Creación": 15\% durante los 2 primeros años en lugar del 25\%)

- Ampliación de las posibilidades de capitalización del desempleo.

- Posibilidad de compatibilizar durante 9 meses el cobro de una prestación por desempleo con la situación de alta como autónomo. Posibilidad (con condiciones) de retomar el cobro de las prestaciones por desempleo a los parados que emprendan y "fracasen".

- Bonificaciones en las cotizaciones sociales para autónomos pluriempleados.

\section{Régimen del auto-emprendedor francés (01/01/2009)}

\section{Marco legal}

Creación mediante la Ley de Modernización de la Economía (LME) del 4 de agosto de 2008, ley basada en una extensión del régimen micro-social que permite calcular y pagar cotizaciones de protección social obligatorias y (opcionalmente) un impuesto liberatorio. Las cotizaciones sociales cubren: la protección por enfermedad y maternidad; las indemnizaciones diarias (salvo en el caso de las profesiones liberales), la Contribución Social Generalizada (CSG) y la Contribución a la Reducción de la Deuda Social (CRDS), las prestaciones familiares, de jubilación y de jubilación complementaria de carácter obligatorio, el régimen de discapacidad y de fallecimiento, así como las cotizaciones ligadas a la formación profesional. Las actividades autónomas adscritas al régimen general de la Seguridad Social (artistas y creadores, por ejemplo, vinculados a la Maison des Artistes) o a la Mutualité Social Agricole (MSA) no pueden beneficiarse de este nuevo régimen.

\section{Condiciones de acceso}

- Cualquier persona física (excepto sociedades y personas jurídicas) que ejerzan su actividad económica a título individual, ya sea de forma principal o complementaria (funcionarios, asalariados, jubilados, estudiantes).

- Volumen de negocios máximo permitido por año (datos de 2014): $82.200 €$ (en el caso de las actividades de venta o de servicios de alojamiento) y de $32.900 €$ (en el caso de prestaciones de servicio o de alquiler de inmuebles...).

- Requerimiento de cualificación necesario en el caso de ciertas actividades artesanales (estética, peluquería, construcción, automóvil...)

\section{Modalidades de salida}

- Automática si el volumen de negocios supera el umbral fijado durante el año de su creación. Los años siguientes, salida en caso de superar los umbrales durante dos años seguidos (y a partir de una cierta cantidad).

\section{Ventajas}

- Franquicia en el Impuesto sobre el Valor Añadido (no necesidad de facturación ni de devolución)

- No necesidad de matriculación en el registro de comercio, ni en el directorio de profesiones (salvo en caso de la actividad artesanal, si bien no se exige el seguimiento de formación obligatoria). 
- Declaración simplificada de las cotizaciones sociales sobre la base de una tasa fija aplicada al volumen de negocios (14,1\% en el caso del comercio, $23,3 \%$ en el caso de las profesiones liberales, del $24,6 \%$ en los servicios)

- Posibilidad de pago liberatorio del impuesto sobre la renta en función del umbral de renta disponible en el hogar (de 1 a 2,2 puntos complementarios sobre las cotizaciones). En caso de ser beneficiario del ACCRE (ayuda para desempleados) existe una cotización reducida.

\section{Cotizaciones fijas establecidas}

\begin{tabular}{|c|c|c|c|c|c|}
\hline $\begin{array}{l}\text { Umbral } \\
(€)\end{array}$ & Actividades & Ejemplos & Cotizaciones & $\begin{array}{l}\text { Con im- } \\
\text { puesto li- } \\
\text { beratorio }\end{array}$ & $\begin{array}{l}\text { Formación } \\
\text { profesional }\end{array}$ \\
\hline 82.200 & $\begin{array}{l}\text { Venta de } \\
\text { mercancías, } \\
\text { restauración, } \\
\text { hostelería }\end{array}$ & $\begin{array}{l}\text { Restaurantes, } \\
\text { ópticas, tien- } \\
\text { das de ropa, } \\
\text { etc. }\end{array}$ & $14,10 \%$ & $15,10 \%$ & 0,10 \\
\hline 32.900 & $\begin{array}{l}\text { Prestación de } \\
\text { servicios co- } \\
\text { merciales }\end{array}$ & $\begin{array}{l}\text { Peluquerías, } \\
\text { zapateros, } \\
\text { fontaneros }\end{array}$ & $24,6 \%$ & $26,3 \%$ & 0,30 \\
\hline 32.900 & $\begin{array}{l}\text { Prestación de } \\
\text { servicios no } \\
\text { comerciales }\end{array}$ & Auto-escuela & $24,6 \%$ & $26,8 \%$ & 0,20 \\
\hline 32.900 & $\begin{array}{l}\text { Actividades } \\
\text { liberales }\end{array}$ & $\begin{array}{l}\text { Arquitecto, } \\
\text { psic ólogo, } \\
\text { etc. (profe- } \\
\text { siones libera- } \\
\text { les) }\end{array}$ & $23,5 \%$ & $25,5 \%$ & 0,20 \\
\hline
\end{tabular}

Ejemplo: una actividad liberal que tenga un volumen de negocios de $30.000 €$, implicará una cotización global de $7.710 €$ y una renta neta anual de $22.290 €(1.875$ $€ /$ mes de media).

\section{Cobertura (si la actividad es complementaria, el régimen de actividad principal se mantiene como referencia)}

- Protección por enfermedad y maternidad/paternidad idéntica a la de los asalariados (en términos de prestaciones y de porcentajes de reembolso con respecto a los pagos efectuados).

- Derecho a indemnizaciones diarias (salvo en el caso de las profesiones liberales) calculadas en función del volumen de negocios con una reducción tasada: $71 \%$ para las actividades de venta, $50 \%$ para las prestaciones BIC (Bénéfices Industriels et Commerciaux) y $34 \%$ para las prestaciones BNC (Bénéfice Non Commercial).

- Jubilación de base y complementaria en función del volumen de negocios

- Prestaciones familiares idénticas a las de los asalariados. 